\title{
Introduction of Imatinib as First-line Therapy for Chronic Myeloid Leukemia in Cuba
}

\author{
Valia Pavón MD, Rafael Gómez MD, Juan C. Jaime MD, Porfirio Hernández MD PhD, Alberto Arencibia MD, \\ Edgardo Espinosa-Martínez MD, Onel M. Ávila MD, Carlos Hernández MD, Alejandro González MD, José Carnot MD, \\ Edgardo Espinosa-Estrada MD, Rosa M. Lam MD, Ana M. Amor PhD, Kalia Lavauth MD, Annia Hernández MD
}

\begin{abstract}
INTRODUCTION Chronic myeloid leukemia is the first malignant disease to be associated with a genetic lesion and is the first leukemia to provide a genotype model conducive to targeted molecular therapy. It is a chronic clonal myeloproliferative disorder, originating in a pluripotent stem cell common to all three hematopoietic lineages, characterized by overproduction of myeloid cells in all stages of maturation.
\end{abstract}

Approval of the use of imatinib in the United States in 2001 and its introduction in the treatment of chronic myeloid leukemia changed the evolution and prognosis of the disease and began the era of molecular therapy for malignancies. Imatinib is highly effective and causes fewer adverse reactions than earlier treatments based on interferon and hydroxyurea.

In Cuba, chronic myeloid leukemia has been treated with interferon since 1998. Starting in 2003, imatinib was gradually introduced for use in newly-diagnosed chronic myeloid leukemia patients.

OBJECTIVE Evaluate the use of imatinib as first-line therapy for chronic myeloid leukemia in a group of Cuban patients, based on hematologic, cytogenetic, and molecular response; overall and eventfree survival rates; and most frequency and severity of adverse reactions.
METHODS During May 2003 to May 2008, 33 newly-diagnosed chronic myeloid leukemia patients ( 25 adults, 8 children; $<6$ months from diagnosis) received a single daily oral dose of imatinib $400 \mathrm{mg}$ from the time of study enrollment. Variables used: (1) to evaluate treatment efficacy: hematologic, cytogenetic, and molecular response; overall and event-free survival; and (2) to evaluate safety: presence of adverse reactions leading to definitive interruption of treatment or death.

RESULTS Complete hematologic response occurred in $100 \%$ of patients, major cytogenetic response in $90.9 \%$, and complete cytogenetic response in $48.5 \%$. Molecular response occurred in $36.4 \%$ of patients. With a mean follow-up of 39 months, overall survival was $96 \%$ and estimated five-year event-free survival was $85 \%$. No adverse reactions occurred in $39.5 \%$ of patients. Adverse reactions most frequently observed were myelosuppression (24.2\%) and digestive disorders (21.2\%). These were followed, in decreasing order, by edema, primarily orbital $(9.1 \%)$, skin depigmentation (3\%), and cardiac arrhythmias (3\%).

CONCLUSIONS In the present study, imatinib was effective first-line therapy for patients with newly-diagnosed chronic myeloid leukemia, as determined by overall and event-free survival rates. No severe adverse reactions were observed.

KEYWORDS Imatinib, chronic myeloid leukemia, cytogenetic response, molecular response, Cuba

\section{INTRODUCTION}

Chronic myeloid leukemia (CML) accounts for $15-20 \%$ of all leukemias and its incidence in Western countries is estimated at 1.5 per 100,000 population.[1] Recent incidence data for Cuba are not available, but if this rate were applied to Cuba's population, approximately 165 new cases would be expected annually.

$\mathrm{CML}$ is a chronic clonal myeloproliferative disorder originating in a pluripotent stem cell common to all three hematopoietic lineages, resulting in overproduction of myeloid cells in all stages of maturation.[2] Its cause is unknown. The first important clue to its pathogenesis came in 1960 when a chromosomal abnormality known as the Philadelphia chromosome $(\mathrm{Ph})$ was discovered in individuals with this disease.[2,3] In the 1980s, it was demonstrated that the $\mathrm{Ph}$ chromosome had a unique fusion gene, known as BCR-ABL.[4] This gene results from the fusion of fragments from two normal genes: $A B L$ on chromosome 9 and $\mathrm{BCR}$ on chromosome 22. In the translocation giving rise to the fusion gene, a breakpoint occurs at some part of the $A B L$ in the opposite direction to exon 2 and simultaneously at the major breakpoint on the BCR gene. As a result, the 5' portion of the $B C R$ gene and the 3' portion of the ABL gene are juxtaposed on a shortened chromosome 22 (the derivative 22q-, or Ph, chromosome). We now know that this gene is responsible for the physiopathological mechanisms of CML, and its constitutively activated tyrosine kinase activity plays an important role in malignant transformation.[5-7]
CML has a biphasic or triphasic course, developing from a chronic phase, characterized by expansion of myeloid cells that maintain normal maturation, to a more aggressive stage that follows two major clinical-hematologic patterns: accelerated phase and blast crisis. In the late phases, leukemic cells lose their capacity to terminally differentiate and the result is an acute leukemia highly resistant to chemotherapy.[8,9]

Treatment strategies for CML have included from control of leukocytosis with busulfan and hydroxyurea, non-specific hematopoiesis suppression with interferon alfa; and allogeneic hematopoietic cell transplantation, currently considered the only curative treatment.[10,11]

In the 1990s, a group of scientists began several research projects to identify kinase-inhibiting chemical compounds.[7] In 1995 and 1996, Buchdunger et al. reported synthesis of a number of compounds that exhibited inhibitory activity against plateletderived growth factor receptor and ABL. Among them, the one known as STI571 was selected for development.[7] It was later demonstrated that this drug, known as imatinib, specifically inhibited or destroyed CML cell lines with the BCR-ABL gene and had little to no effect on normal cells.[12]

Clinical evaluation of imatinib was done through the International Randomized Study of Interferon and STI571(IRIS).[13] IRIS results and imatinib's approval by the US Food and Drug Adminis- 
tration in 2001 led to its adoption as standard first-line therapy for CML.[14,15] IRIS, as a Phase III study, was based on the fact that interferon had been standard therapy for CML, obtaining good results in combination with cytarabine; and on imatinib's outcomes in Phase I and II trials.[16,17] IRIS studied progression-free survival in two patient groups, and secondarily compared quality of life and toxicity profile between the two. Imatinib was found to be effective as first-line therapy in newly-diagnosed chronic-phase CML patients, leading to rates of hematologic response (HR) and cytogenetic response (CR) superior to interferon plus cytarabine.[13]

The introduction of imatinib substantially changed CML course and prognosis and ushered in the era of molecular therapy for malignancies.[18,19]

In Cuba, recombinant interferon alfa was standard treatment for CML from 1998 to 2003,[20] when, due to promising outcomes reported internationally, gradual introduction of imatinib as first-line CML therapy was begun.

This study is the first evaluation in Cuba of imatinib's efficacy as first-line therapy for newly-diagnosed CML, measuring hematologic, cytogenetic, and molecular response (MR); event-free survival (EFS) and overall survival (OS); and safety, as determined by frequency and severity of adverse effects.

\section{METHODS}

Study type and duration An uncontrolled clinical trial was conducted by researchers at Havana's Institute of Hematology and Immunology and collaborators from hematology services throughout Cuba from May 2003 to May 2008.

Inclusion criteria Recent ( $<6$ months) CML diagnosis, positive BCR-ABL gene translocation, and presence of Ph chromosome.

Exclusion criteria Prior malignancy; prior interferon treatment (even if received within six months of diagnosis).

Patients The study included 33 patients with CML diagnosed in various hematology services around the country ( 25 adults and 8 children; 11 female and 22 male). Median age was 29 years (range: $6-72$ years). At time of diagnosis, 17 patients were asymptomatic; splenomegaly was present in 13 , the most frequent symptom; all showed positive BCR-ABL gene translocation in molecular studies; and 17 had a b3a2 breakpoint. Risk was classified by Sokal prognostic scores:[21] 10 patients were classified at low risk, 15 at intermediate risk, and 8 at high risk. Patient characteristics at diagnosis are shown in Table 1. Mean follow-up time was 39 months.

Ethical considerations Study characteristics were explained to all subjects. Written, informed consent was obtained from all participants, or from parents in the case of minors.

The ethics committees of the Hematology and Immunology Institute and participating hospitals approved the study protocol.

Treatment Imatinib: $400 \mathrm{mg}$ capsules (Gleevec, Novartis), in boxes of 30 capsules for oral use. The public health system pro-
Table 1: Baseline patient characteristics $(n=33)$

\begin{tabular}{|c|c|c|}
\hline Characteristic & Median & Range \\
\hline Age (years) & 29 & $6-72$ \\
\hline \multicolumn{3}{|l|}{ Hematology profile } \\
\hline Leukocyte count (x 10\%/L) & 90 & $31-148$ \\
\hline Platelet count (x 10\%/L) & 525 & $441-638$ \\
\hline Hemoglobin (g/L) & 106 & $68-145$ \\
\hline Peripheral-blood blasts (\%) & 3.96 & $0-13.7$ \\
\hline Peripheral-blood basophils (\%) & 3.2 & $0.32-5.44$ \\
\hline Sex & No. & $\%$ \\
\hline Male & 22 & 66.7 \\
\hline Female & 11 & 33.3 \\
\hline \multicolumn{3}{|l|}{ Symptoms } \\
\hline None & 17 & 51.5 \\
\hline Splenomegaly & 13 & 39.4 \\
\hline Fever & 3 & 9.1 \\
\hline \multicolumn{3}{|l|}{ Transcript type } \\
\hline e14a2 (b3a2) & 17 & 51.5 \\
\hline e13a2 (b2a2) & 12 & 36.3 \\
\hline Not tested & 4 & 12.2 \\
\hline \multicolumn{3}{|l|}{ Sokal risk group } \\
\hline Low & 10 & 30.4 \\
\hline Intermediate & 15 & 45.4 \\
\hline High & 8 & 24.2 \\
\hline
\end{tabular}

vided the drug free-of-charge to study subjects. A standard single dose $-400 \mathrm{mg}$ by mouth daily—was used for all participants, since none weighed $<10 \mathrm{~kg}$. Treatment was continuous from time of enrollment. Criterion for temporary treatment interruption was grade 3 or greater myelosuppression (absolute neutrophil count $<1,000$ and platelets $<50,000$ ).

Baseline tests Studies completed before initiating treatment were: complete blood count with differential (CBC),[22] bone marrow aspiration,[23] bone marrow biopsy,[23] G-banded karyotype of bone marrow,[24] BCR-ABL gene translocation by reverse transcriptase-polymerase chain reaction (RTPCR),[24] alanine aminotransferase and serum creatinine levels, echocardiogram, electrocardiogram, and Coombs test.[25]

Follow-up tests Weekly CBCs were done until HR was attained and monthly thereafter. Karyotyping was done every six months; once complete CR was attained, molecular analysis was performed every six months. Liver and renal function tests and electrocardiogram were conducted monthly to evaluate possible adverse reactions to treatment.

\section{Study variables}

Efficacy: HR, CR, MR, EFS, OS, and response types.

Molecular response: BCR-ABL gene translocation: negative, using qualitative RT-PCR.[27]

Event-free survival: Probability of survival from treatment initiation until appearance of an event.[28] Event was defined as death during treatment from any cause, whether or not associated with $\mathrm{CML}$; progression to accelerated phase or blast crisis; loss of complete HR; loss of major CR; or increase in number of leukocytes $>20 \times 10^{9} /$ L. [15] 
Overall survival: Probability of survival from diagnosis until death or withdrawal from study.

Types of Response: Response was classified according to European Leukemia Net criteria;[28] 2009 criteria were not used because the quantitative molecular biology technique for measuring real-time reverse transcriptase-polymerase chain reaction (real-time RT-PCR) was not available.

- Optimal: Major CR at 6 months from initiation of treatment; complete CR at 12 months of treatment.

- Suboptimal: Partial HR at 3 months of treatment; minor CR at 6 months of treatment; major CR at 12 months of treatment; complete CR at 18 months of treatment

- Failure: No HR at 3 months of treatment; no CR at 6 months of treatment; no minor CR at 12 months of treatment; no major CR at 18 months of treatment.

Safety: Adverse reactions to treatment according to guidelines proposed by Deininger et al.: myelosuppression $\geq$ grade 3 (absolute neutrophil count $<1,000$ and platelets $<50,000$ ); localized or generalized edema and fluid retention; gastrointestinal manifestations; secondary musculoskeletal manifestations; hepatotoxicity $\geq$ grade 3 (transaminase elevation $\geq 5$ times upper normal limit).[29]

Severe adverse reactions were defined as those leading to death or permanent suspension of treatment.

Table 2: Variables determining hematologic and cytogenetic responses[26,27]

Complete Hematologic Response (HR)

Variable

Leukocytes

Platelets

Immature cells in peripheral blood

Signs and symptoms of disease

Palpable splenomegaly

Cytogenetic Response* (CR)

Major

Complete

Partial

Minor

No response

*Based on $\geq 20$ metaphase analyses

Statistical analysis The Kaplan-Meier method was used to estimate OS and EFS, with log rank test to analyze differences between variables at a significance level of $p \leq 0.05$. Frequency and percentage tables were used for qualitative variables; measures of central tendency and dispersion, such as median and range, were used for quantitative variables. The statistical software used for data storage and processing was SPSS 12.

\section{RESULTS}

\section{Efficacy}

All patients achieved complete HR in the first three months of treatment. Of the 33 patients, $90.9 \%$ showed major CR: $48.5 \%$ complete and $42.4 \%$ partial. Three patients $(9.1 \%)$ showed minor CR (Table 3). Of patients who had major CR, 28 (93.8\%) achieved it in first 18 months of treatment and two (6.3\%) by 24 months. Mean interval to major CR was 9 months. Molecular response occurred in 12 patients $(36.4 \%)$.

Five-year estimated EFS was $85 \%$, with a mean follow-up of 39 months. Events were loss of major CR in three patients and one
Table 3: Cytogenetic response to imatinib in CML patients* $(n=33)$

\begin{tabular}{|l|r|r|}
\hline Cytogenetic Response & No. & \multicolumn{1}{|c|}{$\%$} \\
\hline Complete & 16 & 48.5 \\
\hline Partial & 14 & 42.4 \\
\hline Minor & 3 & 9.1 \\
\hline No response & 0 & 0.0 \\
\hline Total & 33 & 100.0 \\
\hline
\end{tabular}

*Mean follow-up 39 months

Figure 1: Event-free survival time with imatinib in CML patients $(n=33)$

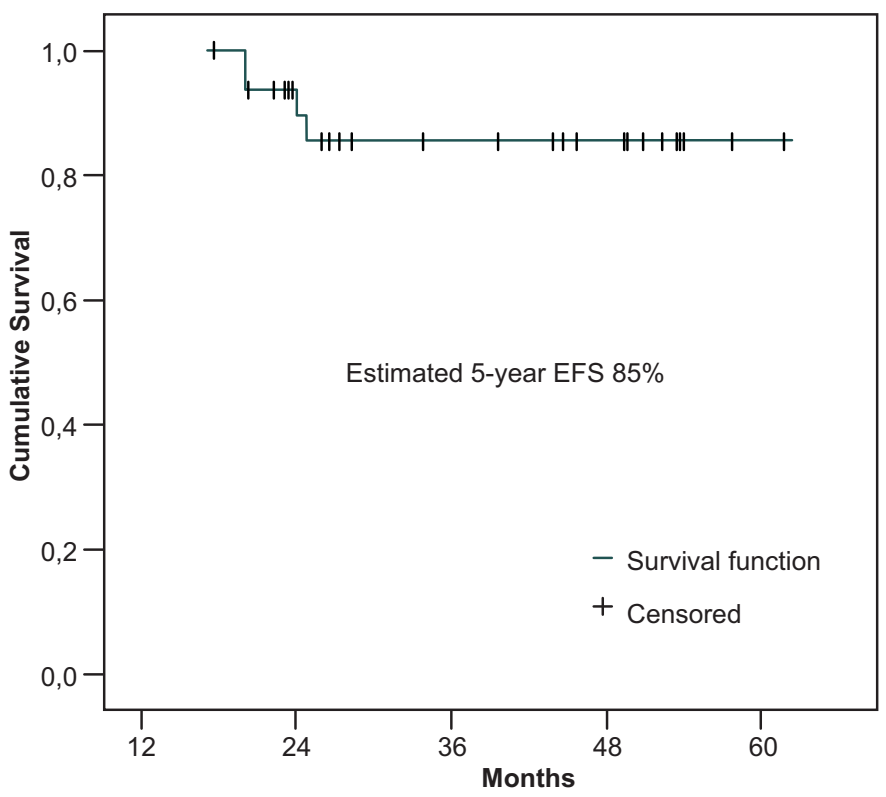

death in blast crisis (Figure 1).There were no significant differences in EFS between pediatric and adult groups ( $p=0.81 \mathrm{log}$ rank) (Figure 2).

There was no association between EFS and interval to major CR. At mean followup (39 months) EFS was $90 \%$ in patients who responded at 6 months, $83 \%$ in those who responded at 12 months, and $100 \%$ and $50 \%$ for those who responded at 18 and 24 months, respectively (Figure 3 ).

With a mean follow-up of 39 months, confidence interval $(\mathrm{Cl}) 20$ 58 months, estimated overall five-years survival rate was $96 \%$.

Of 33 patients included in the study, 11 had an optimal response (including seven of eight children), 18 had a suboptimal response, and treatment failed in four. The cumulative percentage of optimal and suboptimal responses was $87.9 \%$.

There was a highly significant association ( $p=0.0000$, log rank) between EFS and type of response to treatment (Figure 4). Patients who achieved complete $\mathrm{CR}$ had no disease progression; one patient in the group that obtained partial CR showed disease progression, as did two patients in the minor CR group. In this case, lack of $C R$ is predictive of progression with a high degree of statistical significance $(p=0.004)$.

\section{Safety}

In $39.5 \%$ of cases there were no drug-related adverse reactions. None of the adverse events reported were severe. Principal re- 
Figure 2: Event-free survival time with imatinib for CML, adult and pediatric patients $(n=33)$

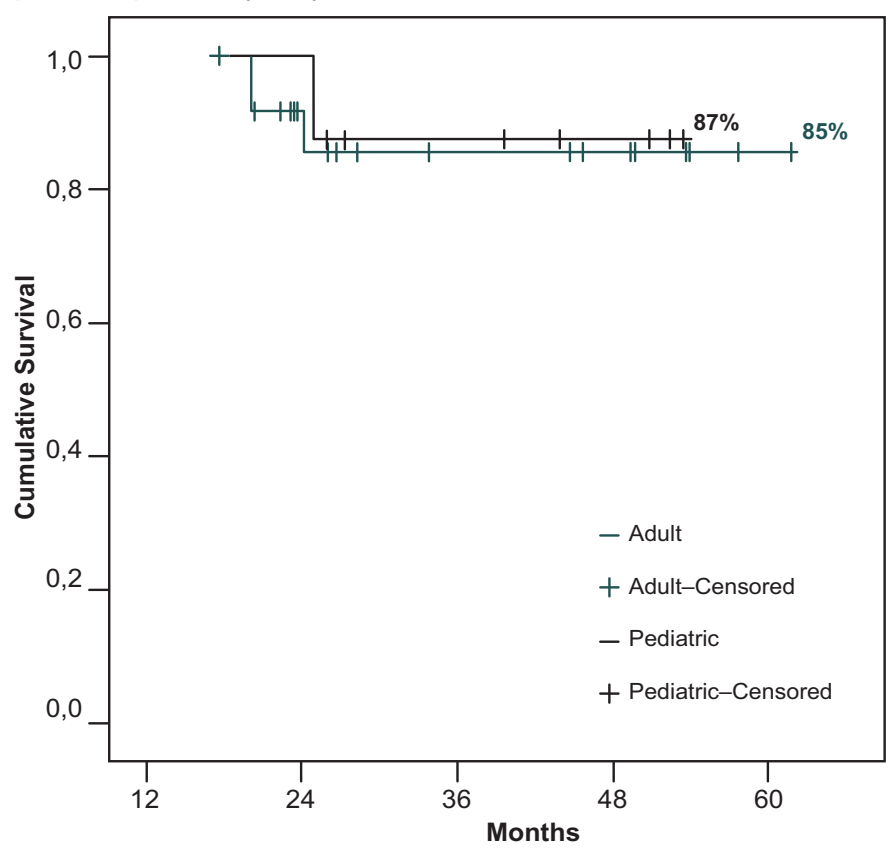

Figure 3: Event-free survival time with imatinib for CML, by interval to major cytogenetic response $(C R)(n=33)$

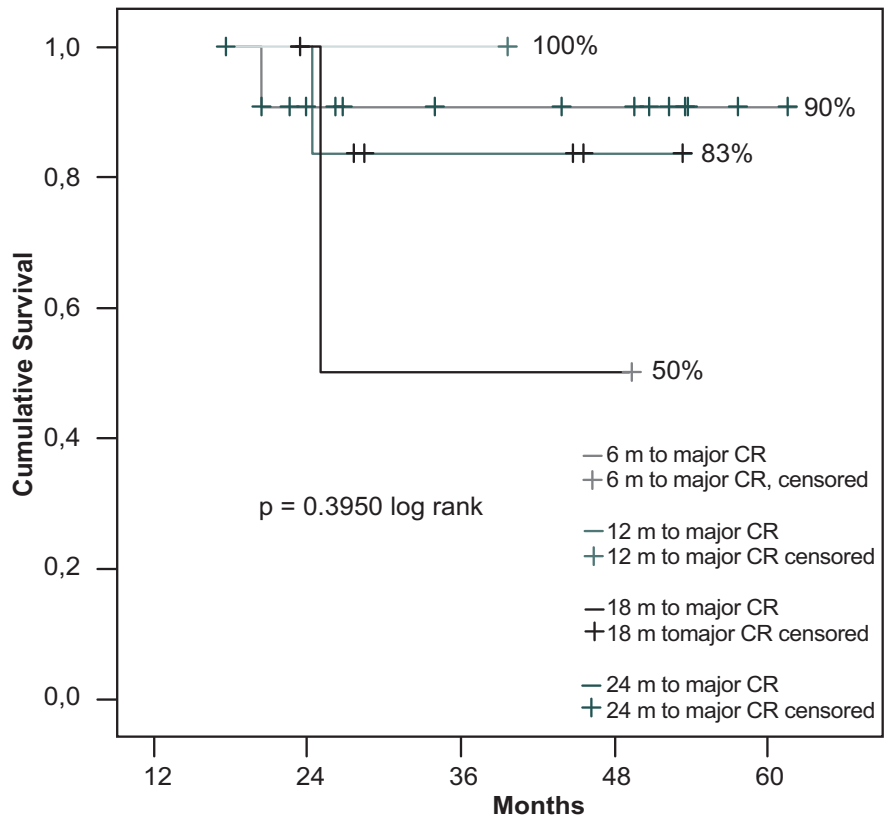

actions were myelosuppression (24.2\%), followed by digestive disorders $(21.2 \%)$. These were followed, in decreasing order, by edema, primarily orbital $(9.1 \%)$, skin depigmentation $(3 \%)$, and cardiac arrhythmias (3\%).

At the end of the study, 32 of 33 patients were alive and two patients had transferred to an alternative protocol with nilotinib, a tyrosine kinase inhibitor used in patients resistant to imatinib.

In summary, treatment with imatinib was safe and effective (Table 4).
Figure 4: Event-free survival time with imatinib, by response type $(n=33)$

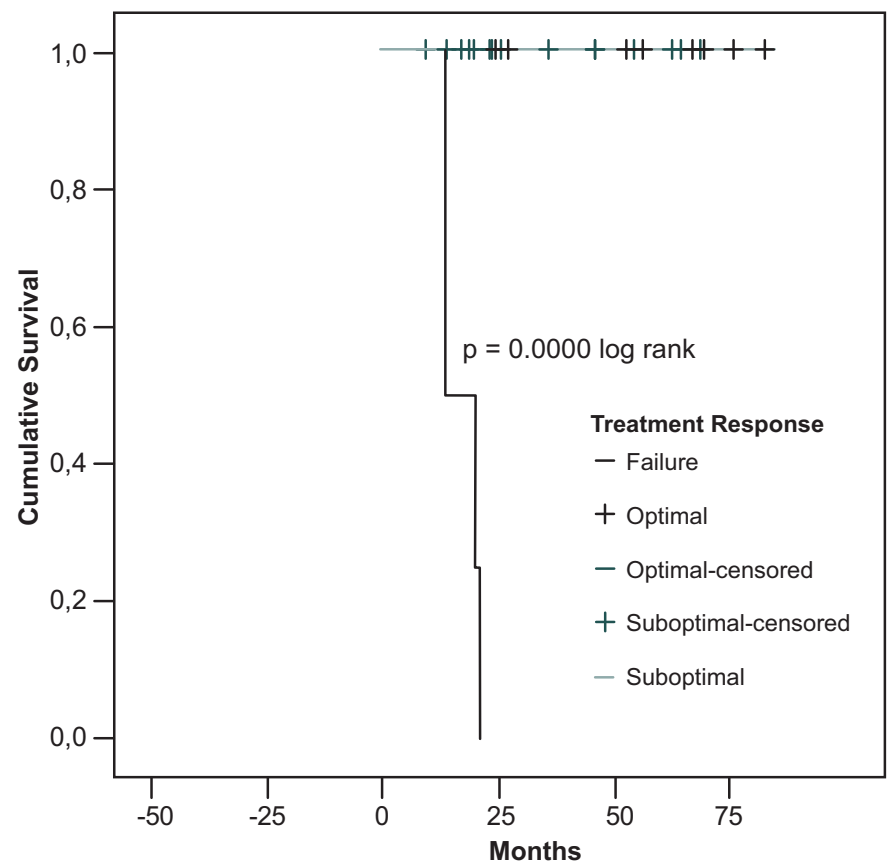

Table 4: Safety and efficacy of imatinib in CML patients

\begin{tabular}{|l|r|}
\hline Variable & $\%$ of cases \\
\hline Hematologic response & $100.0 \%$ \\
\hline Major cytogenetic response & $90.9 \%$ \\
\hline Molecular response & $36.4 \%$ \\
\hline Event-free survival & $85.0 \%$ \\
\hline Overall survival & $96.0 \%$ \\
\hline Severe adverse reactions & $0.0 \%$
\end{tabular}

\section{DISCUSSION}

Imatinib is currently standard first-line therapy for classic or $\mathrm{Ph}+$ CML. Results of this study concur with others showing high levels of response and low rates of adverse effects with imatinib as initial therapy in newly-diagnosed CML.[10,15,30]

An optimal dose aims to achieve maximum antitumor or other therapeutic effect with minimal toxicity. In cases where the standard $400 \mathrm{mg}$ dose has been used for first-line therapy, $100 \%$ obtained complete HR; as in our study, this result appears during the first three months of treatment.[7,8]

The literature reports complete $\mathrm{CR}$ in $60 \%-80 \%$ of newlydiagnosed patients treated with imatinib.[10] The lower rate observed in this study (48.5\%) may be due to sample size constraints and might improve with accrual of larger numbers for analysis. However, our results for major CR (90.9\%) do coincide with experience elsewhere. O'Brien et al. compared imatinib to interferon alfa and low-dose cytarabine in newlydiagnosed chronic-phase CML patients. After a mean follow-up of 19 months, $87.1 \%$ in the imatinib group achieved major CR by 18 months, compared to $34.7 \%$ in the interferon-plus-cytarabine group. The paper concluded that analysis of CR, tolerance, and probability of progression to accelerated phase or blast crisis indicated superiority of imatinib as first-line therapy in newlydiagnosed CML.[13] 
Cytogenetic and molecular monitoring is critical in evaluating treatment success. In the present study, qualitative molecular monitoring techniques were used, more sensitive than quantitative ones since they are able to detect a single leukemia cell in a larger population of healthy cells. Quantitative techniques are very useful for monitoring response evolution, referring to increase or decrease in transcripts, but qualitative evaluation is a more specific method for determining whether or not the patient achieved molecular remission. This permits immediate treatment decisions when a previously negative patient becomes positive,[24]

This study's findings are consistent with other published reports showing low MR rates, even among newly-diagnosed patients. In vitro studies have demonstrated that imatinib primarily inhibits proliferation, without induction of apoptosis in BCR-ABL progenitors. The implication is that imatinib may be able to prevent proliferation of progenitor cells, but unable to eliminate quiescent cells.[7] The opportunity to use quantitative molecular techniques (RT-PCR) would permit establishing better predictive models, as noted by Cortes et al., who showed that achieving major MR is predictive of lasting cytogenetic remission.[31]

Our EFS outcomes were consistent with those reported by other authors.[15] Events were more frequent in patients who were slower to achieve major $\mathrm{CR}$, although the difference was not statistically significant. Disease progression was not observed in patients with complete CR, confirming that CR achievement is an important prognostic factor.

Even though imatinib is generally well tolerated, side effects are not uncommon, including nausea, myelosuppression, edema, fatigue, headache, and joint and muscle pain.[29] Myelosuppression is particularly common when imatinib is used in CML patients in advanced stages of disease,[29] but is infrequent in newlydiagnosed patients,[7] as confirmed in this study.
CML is an uncommon disease-hence the small numbers in this study, an acknowledged limitation. In addition, even though CML can appear at any age, mean age at diagnosis is around 67 years,[31] so pediatric patients are underrepresented.

It is important to continue to investigate imatinib for CML with longer follow-up and higher doses (800 mg/day). Other tyrosine kinase inhibitors, such as nilotinib,[32,33] are also of interest.

This study's importance lies in its analysis of a new therapy introduced Cuba, with results that revolutionize the evolution and prognosis for CML patients compared to the earlier protocol. In addition, it provides our specialized health services with the necessary evidence to offer patients the most internationally advanced and accepted treatment for CML.

\section{CONCLUSIONS}

Although the follow-up period of 39 months can be considered short, this study affirms the value and safety of imatinib as firstline therapy for newly diagnosed patients in the Cuban context. The research also shows the importance of attaining complete cytogenic response for event-free survival, independent of when this response occurs.

\section{ACKNOWLEDGMENTS}

The authors wish to thank the following persons for their collaboration in this study: Aymara Baganet Cobas MD, Carmen V. Díaz Durán MD, Marianela Estrada del Cueto PhD, Antonio A. Bencomo Hernández PhD, Elvira Dorticós Balea MD, Aramís Núñez Quintana MD, Olga Agramonte Llanes MD, Sergio Machín García MD, Andrea Menéndez Veitía MD, Ileana Nordet Carreras MD, John Goldman MD PhD, Julio Fernández Ávila MD, Raquel Fernández Nodarse MD, and Viviana del Cristo Pérez MD. - M

\section{REFERENCES}

1. Melo JV, Barnes DJ. Chronic myeloid leukaemia as a model of disease evolution in human cancer. Nat Rev Cancer. 2007 Jun;7(6):441-53

2. Melo J, Hughes TP, Apperley JF. Chronic myeloid leukemia. Hematology Am Soc Hematol Educ Program. 2003:132-52.

3. Goldman JM, Melo JV. Chronic Myeloid Leukemia-Advances in Biology and New Approaches to Treatment. N Engl J Med. 2003 Oct 9;349(150):1451-64.

4. Radich JP. How I monitor residual disease in chronic myeloid leukemia. Blood. 2009 Oct 15;114(16):3376-81.

5. Quintás-Cardama A, Cortes J. Molecular biology of bcr-abl1-positive chronic myeloid leukemia. Blood. 2009 Feb 19;113(8):1619-30.

6. Kantarjian HM, Cortes J, O'Brien S, Giles FJ, Albitar M, Rios MB, et al. Imatinib mesylate (STI571) for Philadelphia chromosome-positive chronic myelogenous leukemia in blast phase. Blood. 2002 May 15;99(10):3547-53.

7. Deininger $M$, Buchdunger $E$, Druker BJ. The development of imatinib as a therapeutic agent for chronic myeloid leukemia. Blood. $2005 \mathrm{Apr}$ 1;105(7):2640-53.

8. Cortes J, Kantarjian $\mathrm{H}$. Advanced-phase chronic myeloid leukemia. Semin Haematol. 2003 Jan;40(1):79-86. Review.

9. Cortes J, Giles F, O'Brien S, Thomas D, Garcia Manero G, Rios MB, et al. Result of high-dose imatinib mesylate in patients with Philadelphia chromosome-positive chronic myeloid leukemia after failure of interferon-alpha. Blood. $2003 \mathrm{Jul}$ 1;102(1):83-6.

10. Kantarjian H, O'Brien S, Cortes J, Giles F, Rios MB, Shan J, et al. Imatinib mesylate therapy improves survival in patients with newly diagnosed Philadelphia chromosome-positive chronic myelogenous leukemia in the chronic phase: comparison with historic data. Cancer. 2003 Dec 15;98(12):2636-42.

11. Saussele S, Lauseker M, Gratwohl A, Beelen DW, Bunjes D, Schwerdtfeger R, et al. Allogeneic hematopoietic stem cell transplantation (allo SCT) for chronic myeloid leukemia in the imatinib era: evaluation of its impact within a subgroup of the randomized German CML Study IV. Blood. 2010 Mar 11;115(10):1880-5.

12. Savage D, Antman K. Imatinib mesylate. A new oral targeted therapy. N Engl J Med. 2002 Feb 28;346(9):683-93.

13. O'Brien SG, Guilhot F, Larson R, Gathmann I, Baccarani M, Cervantes F, et al. Imatinib compared with interferon and low-dose cytarabine for newly diagnosed chronic phase myeloid leukemia. N Engl J Med. 2003 Mar 13;348(11):9941004

14. Talpaz M, Silver RT, Druker BJ, Goldman JM, Gambacorti-Passerini C, Guilhot F, et al. Imatinib induces durable hematologic and cytogenic responses in patients with accelerated phase chronic myeloid leukemia: results of a phase 2 study. Blood. 2002 Mar 15;99(6):1928-37.

15. Druker B, Guilhot F, O'Brien S, Gathmann I, Kantarjian H, Gattermann N, et al. Five-Year Followup of Patients Receiving Imatinib for Chronic Myeloid Leukemia. N Engl J Med. 2006 Dec 7;355(23):2408-17.

16. Druker BJ, Talpaz M, Resta DJ, Peng B, Buchdunger E, Ford JM, et al. Efficacy and safety of a specific inhibitor of the BCR-ABL tyrosine kinase in chronic myeloid leukemia. N Engl J Med. 2001 Apr 5;344(14):1031-7.

17. Kantarjian H, Sawyers C, Hochhaus A, Guilhot F, Schiffer C, Gambacorti-Passerini C, et al. Hematologic and Cytogenetic Responses to Imatinib Mesylate in Chronic Myelogeneous Leukemia. N Engl J Med. 2002 Feb 28;346(9):645-52.

18. Jabbour E, Jones D, Kantarjian HM, O'Brien S, Tam C, Koller C, et al. Long-term outcome of patients with chronic myeloid leukemia treated with second-generation tyrosine kinase inhibitors after imatinib failure is predicted by the in vitro sensitivity of BCR-ABL kinase domain mutations. Blood. 2009 Sep 3;114(10):2037-43.

19. Jabbour E, Kantarjian H, O'Brien S, Rios MB, Abruzzo L, Verstovsek S, et al. Sudden blastic transformation in patients with chronic myeloid leukemia treated with imatinib mesylate. Blood. 2006 Jan 15;107(2):480-2. 
20. Putintseva E, Fernández N, Pérez Mora L. Factibilidad del estudio en nuestro medio de la acción inhibitoria de alfa-interferones sobre progenitores hematopoyéticos. Rev Cubana Hematol Inmunol Hemoter. 1997;12(1).

21. Sokal JE, Cox EB, Baccarani M, Tura S, Gomez GA, Robertson JE, et al. Prognostic discrimination in «good-risk» chronic granulocytic leukemia. Blood. 1984 Apr;63(4):789-99.

22. International Committee for Standardization in Hematology. Recommendation of measurement of human blood. Am J Clin Pathol. 1977 Oct;68(4):505-7.

23. Lee R, Foerster J, Lukens J, Paraskevas F, Greer J, Rodgers G, editors. Wintrobe's Clinical Hematology. $10^{\text {th }}$ ed. Vol 1. Philadelphia: Lippincott Williams and Wilkins. c1998; 2 vol. Chapter 2; p. 23.

24. Hochhaus A. Minimal residual disease in chronic myeloid leukemia patients. Best Pract Res Clin Haematol. 2002 Mar;15(1):159-78.

25. Rubino M, Kavitsky DM, Nance S. Serologic testing in autoimmune haemolytic anemia (AlHA) with negative direct antiglobulin test (DAT). Transfusion. 2002;42:104S.

26. Kantarjian HM, Cortes JE, O'Brien S, Luthra R, Giles F, Verstovsek S, et al. Long-term survival benefit and improved complete cytogenetic and molecular response rates with imatinib mesylate in Philadelphia chromosome-positive chronic hase chronic myeloid leukemia after failure of interferon alpha. Blood. 2004 Oct 1;104(7):1979-88

27. Kantarjian H, Sawyers C, Hochhaus A, Guilhot F, Schiffer C, Gambacorti-Passerini C, et al. Hematologic and Cytogenetic Responses to Imatinib Mesylate in Chronic Myelogenous Leukemia. N Engl J Med. 2002 Feb 28;346(9):645-52.

28. Baccarani M, Saglio G, Goldman J, Hochhaus A, Simonsson B, Appelbaum F, et al. Evolving concepts in the management of chronic myeloid leukemia: recommendations from an expert panel on behalf of the European Leukemia Net. Blood. 2006 Sep 15;108(6):1809-20.

29. Deininger MW, O'Brien SG, Ford JM, Druker BJ. Practical management of patients with chronic myeloid leukemia receiving imatinib. J Clin Oncol. 2003 Apr 15;21(8):1637-47.

30. Noens L, van Lierde MA, De Bock R, Verhoef G, Zachée P, Berneman Z, et al. Prevalence, determinants, and outcomes of nonadherence to imatinib therapy in patients with chronic myeloid leukemia: the ADAGIO study. Blood. 2009 May 28;113(22):5401-11.

31. Cortes J, Talpaz M, O'Brien S, Jones D, Luthra $\mathrm{R}$, Shan J. Molecular responses in patients with chronic myeloid leukemia in chronic phase treated with imatinib mesylate. Clin Cancer Res. 2005 May 1;11(9):3425-32.

32. O'Brien S, Berman E, Borghaei H, Deangelo DJ, Devetten MP, Devine S, et al. NCCN Clinical Practice Guidelines in Oncology: Chronic Myelogenous Leukemia. J Natl Compr Canc Netw. 2009 Oct;7(9):984-1023.

33. Kantarjian H, Shah NP, Hochhaus A, Cortes J, Shah S, Ayala M, et al. Dasatinib versus Imatinib in Newly Diagnosed Chronic-Phase Chronic Myeloid Leukemia. N Engl J Med. 2010 Jun 17;362(24):2260-70

\section{THE AUTHORS}

Valia Pavón Morán (Corresponding author: valia.pavon@infomed.sld.cu), hematologist, Hematology and Immunology Institute, Havana, Cuba

Rafael Gómez Baute, hematologist, Gustavo Aldereguía Lima Provincial Teaching Hospital, Cienfuegos, Cuba.

Juan C. Jaime Facundo, hematologist, Hematology and Immunology Institute, Havana, Cuba

Porfirio Hernández Ramírez, hematologist with a doctorate in medical sciences, Hematology and Immunology Institute, Havana, Cuba

Alberto Arencibia Núñez, hematologist, Hematology and Immunology Institute, Havana, Cuba

Edgardo Espinosa Martínez, hematologist, Hematology and Immunology Institute, Havana, Cuba
Onel M. Ávila Cabrera, hematologist, Hematology and Immunology Institute, Havana, Cuba

Carlos Hernández Padrón, hematologist, Hematology and Immunology Institute, Havana, Cuba

Alejandro González Otero, hematologist, Hematology and Immunology Institute, Havana, Cuba

José Carnot Uría, hematologist, Hermanos Ameijeiras Hospital, Havana, Cuba.

Edgardo Espinosa Estrada, hematologist, Hematology and Immunology Institute, Havana, Cuba.

Rosa M. Lam Díaz, physician with specialization in biostatistics, Hematology and Immunology Institute, Havana, Cuba.

Ana M. Amor Vigil, biochemist with a doctorate in health sciences, Hematology and Immunology Institute, Havana, Cuba.

Kalia Lavauth Sánchez, geneticist, Hematology and Immunology Institute, Havana, Cuba.

Annia Hernández Cabeza, pathologist, Hematology and Immunology Institute, Havana, Cuba.

Submitted: November 5, 2010

Approved for publication: December 31, 2010 Disclosures: None 